\title{
Music and Cognitive Abilities
}

\author{
E. Glenn Schellenberg \\ University of Toronto, Mississauga, Ontario, Canada
}

\begin{abstract}
Does music make you smarter? Music listening and music lessons have been claimed to confer intellectual advantages. Any association between music and intellectual functioning would be notable only if the benefits apply reliably to nonmusical abilities and if music is unique in producing the effects. The available evidence indicates that music listening leads to enhanced performance on a variety of cognitive tests, but that such effects are shortterm and stem from the impact of music on arousal level and mood, which, in turn, affect cognitive performance; experiences other than music listening have similar effects. Music lessons in childhood tell a different story. They are associated with small but general and long-lasting intellectual benefits that cannot be attributed to obvious confounding variables such as family income and parents' education. The mechanisms underlying this association have yet to be determined.
\end{abstract}

KEYWORDS-music cognition; intelligence; cognitive development

People's eagerness for quick fixes can be seen in the seemingly irrational appeal of crash diets, get-rich-quick schemes, and getsmart-fast programs. Is the claim of music as a route to enhanced intelligence yet another self-improvement fantasy? In the pages that follow, I outline the origins of the claim and evaluate the available evidence.

Intellectual benefits of exposure to music would be noteworthy if (a) they extend to nonmusical abilities, (b) they are systematic and reliable, and (c) they are more likely to result from hearing or playing music than from other activities. Unlike in other cultures, where virtually everyone participates in music making, musical experiences in Western society typically involve listening and, only in some cases, lessons and performing. Music listening is ubiquitous, both purposefully (e.g., listening to the radio) and incidentally (e.g., background music in stores and restaurants). By contrast, relatively few individuals take music lessons for several years. The consequences of music listening

Address correspondence to Glenn Schellenberg, Department of Psychology, University of Toronto at Mississauga, Mississauga, Ontario, Canada, L5L 1C6; e-mail: g.schellenberg@utoronto.ca. are likely to differ quantitatively and qualitatively from those of music lessons.

\section{MUSIC LISTENING}

Widespread interest in the potential benefits of music listening was sparked by the publication of an article (Rauscher, Shaw, \& Ky, 1993) that reported superior spatial abilities for participants who listened to a recording of music composed by Mozart compared to those who sat in silence or listened to relaxation instructions. The finding, known as the "Mozart effect," was publicized widely in the popular media. Although the effect was found to be brief (lasting 10-15 minutes) and the participants were undergraduates, the news captured the public imagination and led to social-policy changes. These included the distribution of a CD of Mozart's music to every baby born in Georgia and the formation of a cottage industry of music recordings designed to make infants smarter. Presumably, the underlying rationale was that if the short-term effect is reliable, long-term exposure to music in infancy — when brain plasticity is greatest—might facilitate neural connections that could have long-term impact.

Subsequent replication attempts met with mixed success (Chabris et al., 1999), however, which could be attributable to the weakness of the effect or the reliance on group testing (Schellenberg, in press). The original authors proposed that passive listening to music composed by Mozart primed spatial abilities in particular, and they attributed the replication failures to the wrong music or the wrong task. But their proposal of cross-modal priming between two unrelated domains is at odds with the available research. Priming is a relatively robust psychological phenomenon that occurs between stimuli with an obvious link. In language, for example, cross-modal priming effects are evident for subsequent presentations of the same word, a related word, a homonym, and the sentential structure implied by the word (i.e., repetition, semantic, phonological, and syntactic priming, respectively).

The meta-analysis in Chabris et al. (1999) motivated speculation that the Mozart effect, when evident, could be explained as an artifact of arousal. Optimal levels of arousal (i.e., physical and mental activation) have widespread, facilitative effects on performance. In line with this view, a colleague and I (Nantais and Schellenberg, 1999) replicated the Mozart effect (compared to sitting in silence) but we also found a "Schubert effect" of 
identical magnitude. When listening to Mozart was contrasted with listening to a narrated story, the effect disappeared (see Fig. 1) but performance interacted with preferences. Listeners who preferred Mozart performed better after listening to Mozart than to the story. Listeners who preferred the story showed the opposite pattern (a "Stephen King effect").

Thompson, Husain, and I (Thompson, Schellenberg, \& Husain, 2001) subsequently formulated the arousal-and-mood hypothesis: Listening to Mozart is one example of a stimulus that influences the perceiver's arousal level and mood, which can affect performance on a variety of cognitive tasks. Our participants heard a fast-tempo piece by Mozart in a major (happysounding) key, or a slow-tempo piece by Albinoni in a minor (sad-sounding) key. As predicted, we observed a Mozart effect (compared to silence) but no "Albinoni effect" on a test of spatial abilities. We also found that arousal and mood were higher and more positive after listening to Mozart than after listening to Albinoni. The effect size of the Mozart advantage on the spatial test was virtually identical in magnitude to the Mozart advantage in arousal and mood. When changes in arousal or mood were held constant by statistical means, the Mozart advantage on the spatial test disappeared. In another study (Husain, Thompson, \& Schellenberg, 2002), the tempo (fast or slow) and mode (major or minor) of the same Mozart piece were manipulated before listeners completed a spatial task. The manipulations led to different arousal levels and moods across conditions, which, in turn, accounted for the majority of the variance in spatial abilities. Yet another study tested nonspatial abilities after undergraduates listened to Mozart or to Albinoni (Schellenberg, Nakata, Hunter, \& Tamoto, in press). When the listening experience resulted in differences in arousal and mood, performance on a test of processing speed was also better following Mozart than it was following Albinoni.

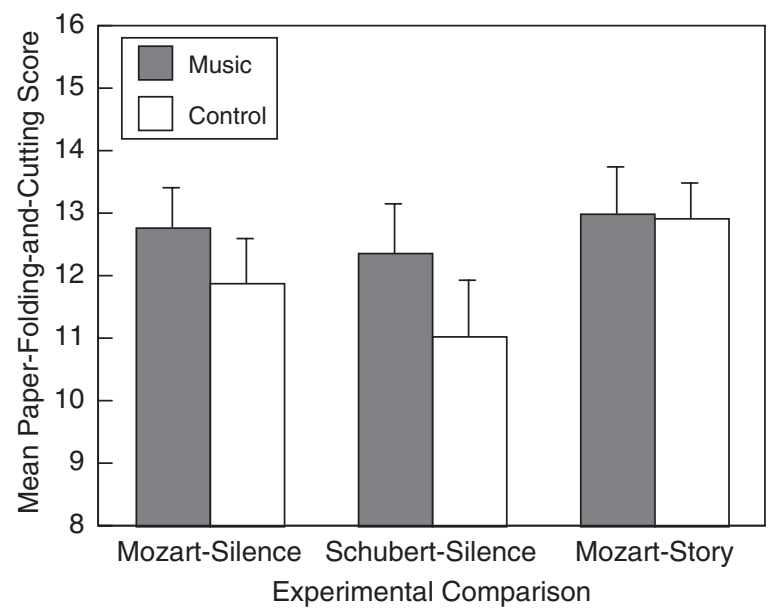

Fig. 1. Mean scores on the paper-folding-and-cutting spatial test in the music-listening and control conditions (Nantais \& Schellenberg, 1999). The figure shows a Mozart effect (left), a Schubert effect (middle), and, when the control condition involved listening to a story, no effect (right).
Paper-and-pencil measures of arousal and mood are not available for children, but the available findings reveal enhanced cognitive performance after listening to music that is thought to be arousing and pleasant for the age group under investigation. For example, Hallam and I (Schellenberg and Hallam, in press) reported a "Blur effect" for 10- and 11-yearolds, who performed better on a spatial test after listening to pop music (by Blur and other bands) compared to music composed by Mozart or a scientific discussion. In a test of creativity among younger children (Schellenberg et al., in press), 5-year-olds drew with crayons after listening to Mozart, Albinoni, or familiar children's songs, or after singing familiar songs. Drawing times were longer, and the drawings were judged to be more creative, for the children exposed to familiar songs (a "children's play song effect"). The effects did not differ between the listening and singing groups (see Fig. 2).

In sum, music listening (or singing) can lead to enhanced performance on a variety of tests of cognitive ability. These effects are mediated by arousal and mood and are unlikely to differ from those that arise as a consequence of exposure to nonmusical stimuli that have similar emotional impact (e.g., giving participants a cup of coffee or a small bag of candy; see Isen, 2000; Smith, Osborne, Mann, Jones, \& White, 2004). Listening to music composed by Mozart does not have unique or special consequences for spatial abilities. Rather, upbeat, age-appropriate music can improve listeners' arousal level and mood, at least for short periods. In turn, effects of arousal and mood extend beyond measures of spatial ability to tests of processing speed and creativity. In principle, similar short-term cognitive benefits might be evident among infants, whose arousal level is altered by exposure to maternal singing (Shenfield, Trehub, \& Nakata, 2003). It is well established that infants perform best in the laboratory when they are alert and content.

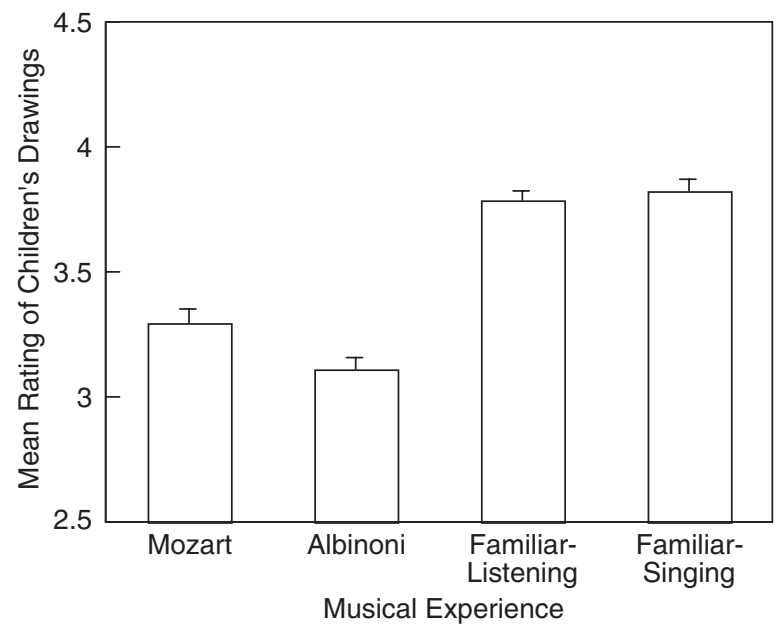

Fig. 2. Mean adult ratings of children's drawings (Schellenberg et al., 2005). Children drew after one of four musical experiences: listening to Mozart, listening to Albinoni, listening to familiar children's songs, or singing familiar songs. Adult raters (blind to group membership) rated the drawings. Higher ratings indicate more favorable appraisals of the drawings relative to a baseline (no music) drawing. 


\section{MUSIC LESSONS}

We turn now to the issue of whether music lessons confer nonmusical benefits. I (Schellenberg, 2004) conducted the only controlled experiment to date that included random assignment of individual children to music lessons or comparison conditions. One hundred and forty-four 6-year-olds were administered an entire standardized IQ test (the Wechsler Intelligence Scale for Children-III, or WISC-III) before entering first grade (at age 6) and again between first and second grade (at age 7). In the interim, two groups of children received 36 weeks of keyboard or vocal instruction. Two control groups received drama lessons or no lessons. All four groups had reliable increases in full-scale IQ from the first to the second testing session. Such increases are a known consequence of attending school. The two music groups did not differ in this regard, nor did the two control groups, but the increase in IQ was greater for the music groups than for the control groups (see Fig. 3). This difference was not a consequence of elevated performance on a specific subset of intellectual abilities (e.g., verbal or spatial). Compared to the control groups, the music groups had larger increases across the four main areas of intellectual ability measured by the WISC-III (i.e., the four index scores, see Fig. 3). An incidental finding was that the drama group had increases in adaptive social skills that were larger than those in the other three groups.

This experiment provided evidence that music lessons cause improvements in intellectual ability. My finding of broad intellectual benefits of music lessons is also consistent with the literature as a whole (Schellenberg, in press), which includes reports of positive associations between music lessons and reading, mathematical, verbal, and spatial abilities. Would music lessons of longer duration be accompanied by larger in-

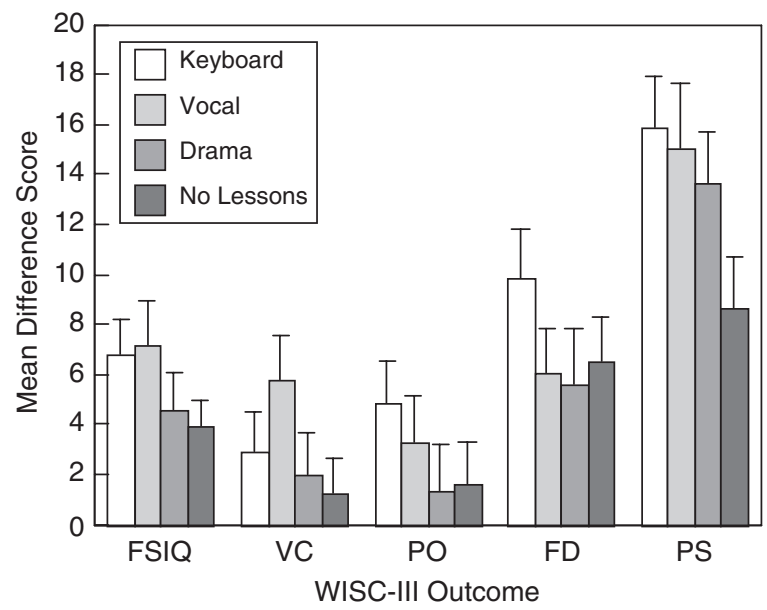

Fig. 3. Mean difference scores on the Wechsler Intelligence Scale for Children-III (WISC-III) outcome measures for groups of children receiving keyboard lessons, vocal lessons, drama lessons, or no lessons (Schellenberg, 2004). The music groups had larger increases than the drama-lessons and no-lessons (control) groups. (FSIQ $=$ Full-Scale IQ, VC $=$ Verbal Comprehension Index, $\mathrm{PO}=$ Perceptual Organization Index, FD = Freedom from Distractibility Index, PS = Processing Speed Index.) tellectual benefits? Because longer-term experimental studies would likely suffer from differential attrition across conditions, I (Schellenberg, 2005) tested this question correlationally. In contrast to previous research, I also measured confounding variables such as family income and parents' education, which were held constant in the statistical analyses.

The participants were 147 children and 150 undergraduates. For the children, outcome measures included the entire WISCIII as well as a standardized test of educational achievement and grades in school. The number of months of music lessons had a modest but positive association with each outcome variable that remained reliable when family income, parents' education, and involvement in nonmusical activities were held constant. Once again, the effects were broad, extending across the four index scores and the different areas of academic achievement (math, spelling, reading) but not to social skills. Involvement in nonmusical out-of-school activities was not predictive of IQ, academic achievement, or social behavior. For the undergraduates, the outcome measure was an entire adult IQ test (the Wechsler Adult Intelligence Scale-III, or WAIS-III). The association between years of playing music regularly and IQ was smaller than the one observed in childhood but it was statistically reliable even after accounting for individual differences in family income and parents' education. These correlational findings extend those of the experimental study by showing that real-world effects of musical training on intellectual abilities are (a) larger with longer periods of training, (b) long lasting, (c) not attributable to obvious confounding variables, and (d) distinct from those of nonmusical out-of-school activities.

What are the underlying mechanisms driving the association between music lessons and intellectual ability? One possibility is that because music lessons are school-like, the intellectual benefits of attending school are exaggerated by the positive impact of additional schooling on IQ. From this perspective, drama lessons might be insufficiently school-like (e.g., they include pretending and dressing up), although other out-ofschool activities such as reading or chess lessons ought to have benefits similar to music. Music lessons would be special only because they represent a school-like activity that many children enjoy and choose to do on a regular basis.

A second possibility is that the association stems from the constellation of abilities that music lessons train and improve-abilities including focused attention and concentration, memorization, reading music, fine-motor skills, expressing emotions, and so on. Although the association could be a consequence of improvement in one of these abilities or a particular subset, the diffuse nature of the association implicates the contribution of multiple factors. The particular type of music lessons (e.g., the instrument or teaching method) might have more specific effects on outcome measures other than IQ. For example, keyboard lessons are as good as drama lessons in improving children's ability to decode the emotions conveyed by prosody in speech, but voice lessons have no beneficial effect (Thompson, Schellenberg, \& Husain, 2004). 
A third possibility is that music promotes intellectual development because of its inherently abstract nature. For example, a tune is defined solely by relational information. A listener can identify a particular tune (e.g., "Yankee Doodle") when it is played fast or slow, at a high or a low pitch level, on a piano or a guitar, and so on. In other words, tunes are abstractions. Listeners' representations must generalize even farther to patterns that have similar but not identical relational information (e.g., variations on a theme). To illustrate, the opening bars of Beethoven's Fifth Symphony have a repeated motive that varies in absolute pitch (different starting tone) and in relative pitch (major third then minor third), yet listeners hear the second motive as a repetition because of its identical rhythm and melodic contour. Learning to think abstractly and to recognize musical similarities across contexts could facilitate intellectual development more generally.

Finally, learning a musical language could have cognitive benefits similar to those evident in bilingual children (Craik \& Bialystok, 2005). Although this view has intuitive appeal because music and language are both auditory communication systems, the positive effects of bilingualism are evident for fluid intelligence (i.e., executive control) but not for crystallized intelligence (e.g., knowledge acquired through experience, such as vocabulary), whereas the effects of music lessons appear to extend to both domains.

\section{CONCLUSION}

Does music make you smarter? The answer is a qualified yes. Music listening and music lessons can lead to short-term and long-term cognitive benefits, respectively. This positive answer is qualified because the short-term benefits of music listening do not appear to differ from those associated with other stimuli that optimize arousal level or elicit mild positive affect. The mechanisms driving the intellectual benefits of music lessons remain more obscure. Similar benefits could be derived from other outof-school activities that are similarly school-like. Nonetheless, music lessons might be special in this regard because (a) they are a school-like activity that many children enjoy, (b) multiple skills are trained in music lessons, (c) music is a domain that improves abstract reasoning, or (d) acquiring musical knowledge is similar to acquiring a second language. Future research could identify the underlying mechanisms more clearly.

Is music a quick fix to the problem of intelligence? The answer is most definitely no. Short-term positive benefits of music listening dissipate rapidly as listeners' arousal level and mood fluctuate with time and experience. Although music lessons have relatively long-term benefits, the effort involved (weekly lessons, daily practice) can hardly be construed as a quick fix. Depending on the perspective of the child and his or her parents, the benefits of a few IQ points may or may not be worth the costs in time, money, and effort. Moreover, different extracurricular activities (e.g., drama lessons) have salutary effects in other domains (e.g., social skills) that could be as valuable as the modest increase in
IQ attributable to music lessons. The simplest take-home message is that extracurricular activities benefit child development.

\section{Recommended Reading}

Isen, A. (2000). (See References)

Schellenberg, E.G. (2004). (See References)

Schellenberg, E.G. (in press). (See References)

Acknowledgments-Funded by the Natural Sciences and Engineering Research Council of Canada and the International Foundation for Music Research. Craig Chambers, Kate McLean, and Sandra Trehub provided helpful comments on earlier versions of the manuscript.

\section{REFERENCES}

Chabris, C.F., Steele, K.M., Dalla Bella, S., Peretz, I., Dunlop, T., Dawe, L.A., Humphrey, G.K., Shannon, R.A., Kirby, J.L. Jr., Olmstead, C.G., \& Rauscher, F.H. (1999). Prelude or requiem for the 'Mozart Effect'? Nature, 400, 826-828.

Craik, F., \& Bialystok, E. (2005). Intelligence and executive control: Evidence from aging and bilingualism. Cortex, 41, 222-224.

Husain, G., Thompson, W.F., \& Schellenberg, E.G. (2002). Effects of musical tempo and mode on arousal, mood, and spatial abilities. Music Perception, 20, 151-171.

Isen, A.M. (2000). Positive affect and decision making. In M. Lewis \& J.M. Haviland-Jones (Eds.), Handbook of Emotions (2nd ed., pp. 417-435). New York: Guilford.

Nantais, K.M., \& Schellenberg, E.G. (1999). The Mozart effect: An artifact of preference. Psychological Science, 10, 370-373.

Rauscher, F.H., Shaw, G.L., \& Ky, K.N. (1993). Music and spatial task performance. Nature, 365, 611.

Schellenberg, E.G. (2004). Music lessons enhance IQ. Psychological Science, 15, 511-514.

Schellenberg, E.G. (2005). Long-term positive associations between music lessons and IQ. Manuscript submitted for publication.

Schellenberg, E.G. (in press) Exposure to music: The truth about the consequences. In G.E. McPherson (Ed.), The child as musician: A handbook of musical development. Oxford, U.K.: Oxford University Press.

Schellenberg, E.G., \& Hallam, S. (in press). Music listening and cognitive abilities in 10 and 11 year olds: The Blur effect. Annals of the New York Academy of Sciences.

Schellenberg, E.G., Nakata, T., Hunter, P.G., \& Tamoto, S. (in press). Exposure to music and cognitive performance: Tests of children and adults. Psychology of Music.

Shenfield, T., Trehub, S.E., \& Nakata, T. (2003). Maternal singing modulates infant arousal. Psychology of Music, 31, 365-375.

Smith, B.D., Osborne, A., Mann, M., Jones, H., \& White, T. (2004). Arousal and behavior: Biopsychological effects of caffeine. In A. Nehlig (Ed.), Coffee, tea, chocolate, and the brain: Nutrition, brain, and behavior (pp. 35-52). Boca Raton, FL: CRC Press.

Thompson, W.F., Schellenberg, E.G., \& Husain, G. (2001). Arousal, mood and the Mozart effect. Psychological Science, 12, 248-251.

Thompson, W.F., Schellenberg, E.G., \& Husain, G. (2004). Decoding speech prosody: Do music lessons help? Emotion, 4, 46-64. 